\title{
APPLICATION OF REMOTE SENSING TO ASSESS THE BIOPHYSICAL CHARACTERISTICS OF PALM OIL TREES FOR ECOLOGICAL STUDY
}

\author{
MOHD RAZALI SHERIZA*, MUSA FATIN NURUL \\ AND NURUDDIN AHMAD AINUDDIN
}

\begin{abstract}
Institute of Tropical Forestry and Forest Products (INTROP), Universiti Putra Malaysia, Serdang, Selangor, Malaysia

*Corresponding author e-mail: sherizasmr@gmail.com, sheriza@upm.edu.my
\end{abstract}

Received: $15^{\text {th }}$ July 2020 , Accepted: $5^{\text {th }}$ October 2020

\begin{abstract}
Oil palms are an important crop for Malaysia as the main crop cultivated from agricultural lands for economic purposes. The livelihood of small growers is, in fact, very dependent on that industry. The present study employs the application of remote sensing of higher resolution to assess the biophysical characteristics of oil palms stands for a plantation in Lenggeng, Negeri Sembilan, Malay Peninsula. Band combination with the use of natural, red, blue bands and red-edge spectrum was employed to obtain early information on the oil palm stands at the site. We subsequently employed fish eye camera to collect information on leaf area index at the field. The study also measured the height and diameter at breast height of all plots established in the site. Finally, correlation was performed to establish the relationships between height-to-leaf area index relations. Diameter at breast height measuring points was scattered at the upper part of the line that formed negative relationships $\left(\mathrm{R}^{2}=-0.0313\right)$. Height was positively associated with leaf area index, a bit weaker $\left(R^{2}=0.2323\right)$. Interpolation found plots at varying elevation level. Maximum height of the trees was recorded at the highest elevation in the site, presumably due to the higher solar radiation that enhances photosynthesis. Our study demonstrates the usefulness of the finding for implementation elsewhere in assessing the biophysical characteristics of oil palm trees. The study leads to further understanding of oil palms, specifically the biophysical characteristics associated with plant productivity assessment.
\end{abstract}

Keywords: Oil palm, income generation, vegetation indices

\section{INTRODUCTION}

Oil palm is one of Malaysian highest economic contributors. The annual production of oil palm crude is approximately a million tonnes. Currently, Malaysia accounts for $28 \%$ of world palm oil production and $33 \%$ of the world exports. If taken into the account of other oils and fats production, Malaysia accounts for $9.5 \%$ and $19.7 \%$ of the world's total production and exports of oils and fats (MPOC, 2014). Therefore, the agricultural land intended for cultivation of oil palm should be assessed based on recent available technology.

Tropical forest in the region of Peninsular Malaysia is characterized by southwest monsoon season (SWM), the dry season and particularly extreme in the western part of the 
Sheriza M.R ., Nurul Fatin M., Ainuddin, N.A : Application of remote sensing to assess the biophysical characteristics of palm oil trees for ecological study

peninsular (Jamaludin et al., 2010). The continuous dry season can result in a prolonged drought that can impact on the environmental, agricultural and socioeconomic circumstances (Bhuiyan et al., 2006). Drought also affects the agriculture crop production and had a negative impact that depreciates life quality in Malaysia, especially in the Peninsular Malaysia (Wan Zin et al., 2013). Regardless, the optimum humid tropical condition, high precipitation rates with warm temperature of $24^{\circ} \mathrm{C}-32^{\circ} \mathrm{C}$ and high solar radiation in Malaysia are favourable to the cultivation of this crop species for optimum growth (Corley \& Tinker, 2003). This makes Peninsular Malaysia very suitable for oil palm cultivation.

Remote sensing is the best application for monitoring agricultural lands, especially for monitoring oil palm in tropical areas (Cheng et al., 2016, 2018; Tan et al., 2014). As of present, remote sensing is recognized as a great and potential technique for monitoring vegetation on land for commercial crops such as oil palm, rubber, cocoa, corns and others agricultural lands. For instance, Cheng et al. (2018) performed mapping of the oil palm extent in Malaysia using ALOS-2 PALSAR-2 data in 2017. Further, study on utilization of band combination to validate ground bio-physical data specifically to delineate oil palm plantation area can also be performed because the satellite spectral bands strength that demonstrate good spectral performance combined with ground and expert's interpretation.

Specifically, bands at certain spectral performing as criteria for specific environmental disaster such as disease outbreak are analysed by low resolution images. With the advent of technology, higher resolution image can be afforded at lower cost compared to early age satellite launched. Remote sensing can connect between images derived from satellite in the sky and bio-physical of the tree on the ground. Data derived from the free available source of Moderate Resolution Spectroradiometer (MODIS) can be used for a drought study in Peninsular Malaysia (Mohd Razali et al., 2015; Razali et al., 2015). Besides, MODIS and PALSAR satellite data was employed for forest cover classification, respectively (Longépé et al., 2011; Sheldon et al., 2012).

The definitions of LAI have been developed over the past decades by scientists from several disciplines for a variety of uses, such as for forest group succession determination and future simulation. Zheng \& Moskal (2009) review a comprehensive definition of LAI, including the description of ToLAI and PLAI. ToLAI is Total Leaf Area Index whereas PLAI is Projected LAI. ToLAI is defined as the total one-sided area of photosynthetic tissue per unit of ground surface area (Watson, 1947). PLAI, on the other hand, is defined as the horizontal area that is cast beneath a horizontal leaf from a light at infinite distance above it (Ross, 1981). LAI of oil palm depends on the mean area of individual fronds, the number of fronds per palm and the planting density. The LAI value for oil palm stands in Malaysia's case exceed 2.0 (Roslan et al., 2004). The study explained LAI as:

$$
\operatorname{Ln}(1-f)=-k(L-a) \ldots \text { Equation }(1)
$$

Where $\mathrm{L}$ is leaf area index; $\mathrm{f}$ is fractional interception of photosynthetically active radiation (PAR), a is constant; and finally, $\mathrm{k}$ is extinction coefficient.

LAI is seen as an essential biophysical that must be extracted from the tree based on a destructive method and hemispherical photography. A study conducted in oil palm plantation in Bangi nearby Kuala Lumpur demonstrates that hemispherical photography enables the derivation of LAI, hence cutting the cost and save time (Awal et al., 2010). Other study in Querência municipality of Mato Grosso located in the transition zone between the savannas (Cerrado) and the tropical forest also demonstrate the capability of estimating LAI from hemispherical photography (Galvão et al., 2011). The study investigates the cause of 
dry season by means of satellite imageries application. Meanwhile, research conducted in Sabah and Sarawak of East Malaysia region demonstrate the assessment of LAI and microclimate in the tropical forest and oil palm plantation. The study is guided by LAI as a physical metric of vegetation structure that is relevant to the microclimatic processes. Plant canopies was found to be a huge impact on the amount of solar radiation and air temperature near the ground (Hardwick et al., 2015).

This study enlists hemispherical photography to conduct an inventory campaign in an oil palm plantation to collect information on palm tree height $(\mathrm{H})$, diameter at breast height (dbh) and LAI. Here, we investigated the relationship between height and dbh with vegetation cover as described by LAI in a highly economical crop plantation. At the same time, we also take advantage of the pre-existing data on elevation from other related project to develop a spatial interpolation of elevation to observe LAI distribution in the study area.

\section{MATERIALS AND METHODS}

\section{The experimental site}

The study region covered palm oil plantation located in the district of Lenggeng, Negeri Sembilan $\left(2^{\circ} 51^{\prime} 38.66^{\prime \prime} N, 1^{\circ} 57^{\prime} 21.64 " E\right)$, Peninsular Malaysia (Figure 1). According to Malaysian Palm Oil Board, cultivation of oil palm has reportedly expanded dramatically over the past decade. This is evidenced from the export of oil palm with $12 \%$ increment, which amounted to 27.86 million tons in 2018 (MPOB, 2020). This pushes the state into the spotlight for this type of study.

Fig. 1: The location of Peninsular Malaysia in Southeast Asia with different states forming the peninsular zone (above) and the precise location of the study area in Negeri Sembilan (below).

The map depicted the distance to each station from meteorological stations and the station points marked with unique colours.

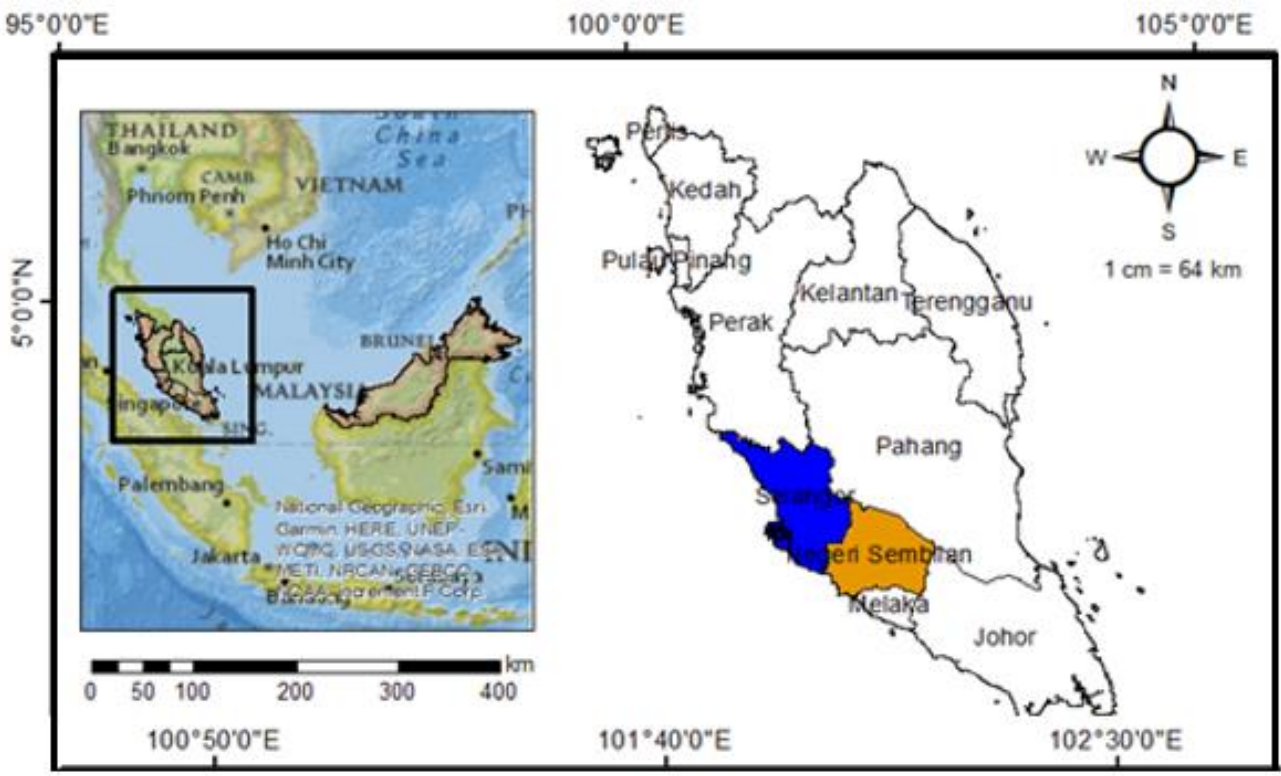


Sheriza M.R ., Nurul Fatin M., Ainuddin, N.A : Application of remote sensing to assess the biophysical characteristics of palm oil trees for ecological study

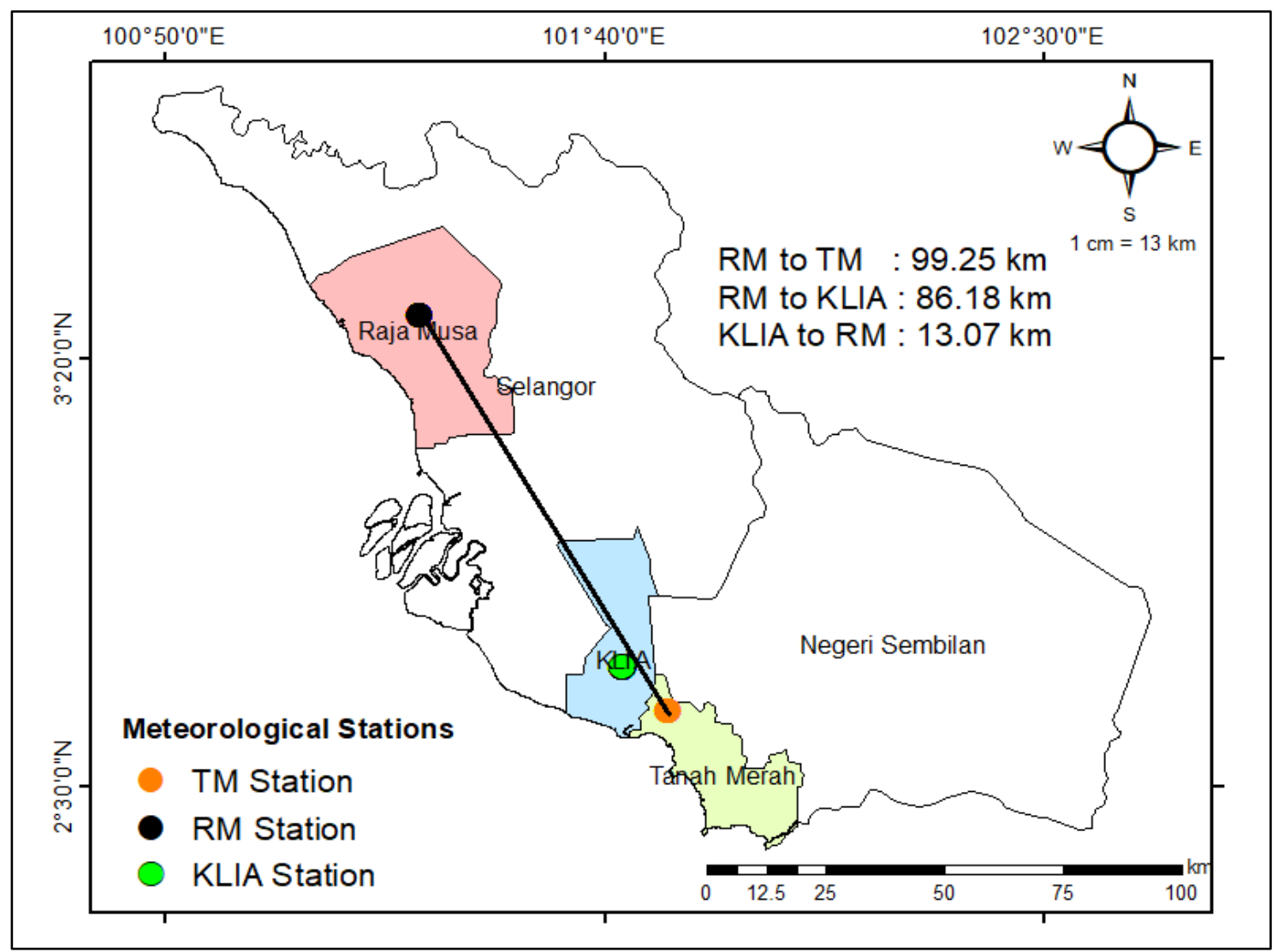

Fig. 2: Average annual precipitation from 1998 to 2017

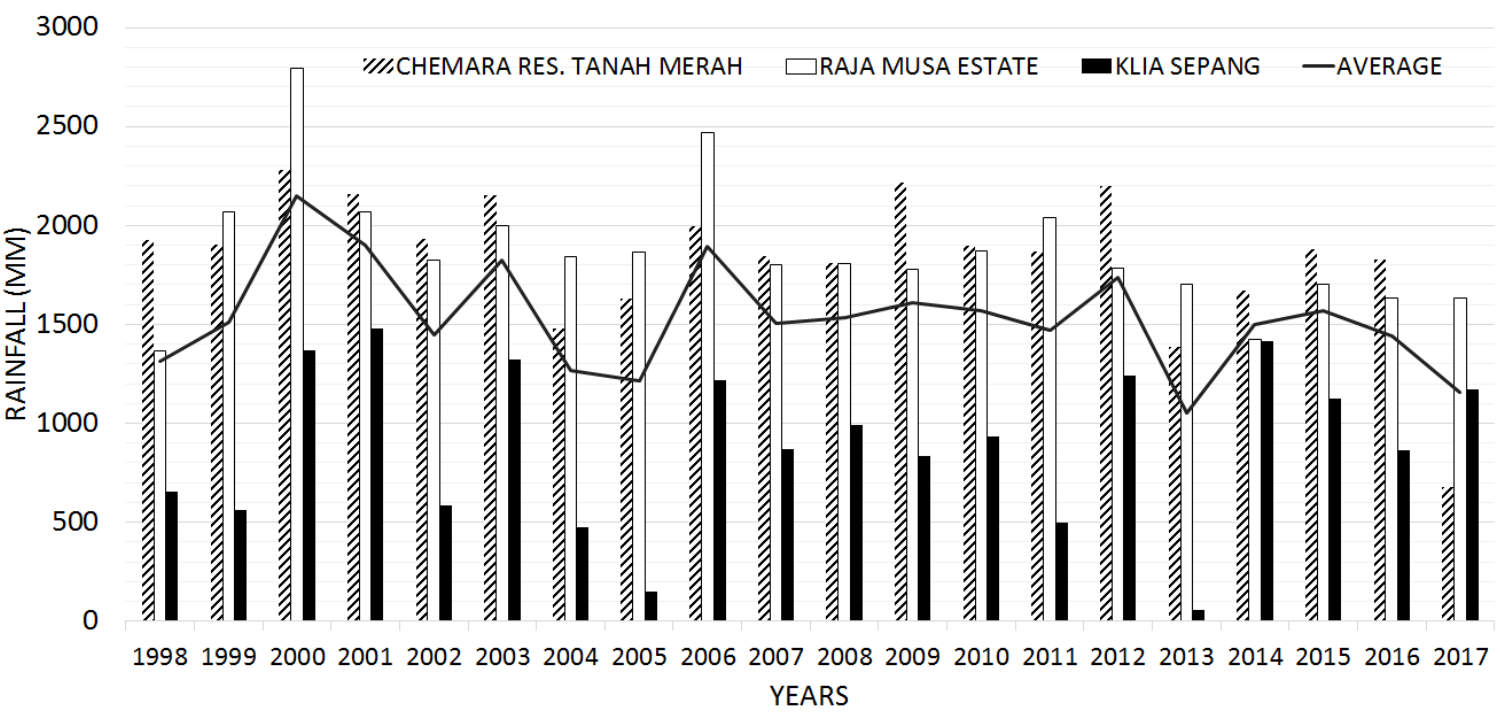


The mean annual precipitation ranged from $1000 \mathrm{~mm}$ to $2100 \mathrm{~mm}$ from 1998 to 2017 that was collected from Chemara Res. Tanah Merah, Raja Musa Estate and KLIA Sepang meteorological stations (Figure 2). Specifically, the plantation is 16 years old with oil palm trees owned by Felcra Berhad, Felcra Berhad Kawasan Gagau. A preliminary visit to the site was accompanied by the plantation manager, Mr. Rahim Omar. A comprehensive information and overview of the site were obtained based on his experience and management skills. Productivity rate, fertilization scheme, drought effect on the trees as well as other relevant information were gathered during the visit. The plantation ground was well managed and lightly covered with oil palm leaves and there was scarcely empty fruit bunch left behind. The manager emphasized that specific plants such as shrubs was planted to protect moisture of the ground. Annual crop productivity of oil palm was estimated as an average 146 per hectare with 8 to 10 fruit bunches per tree. Pruning was performed once a year to maintain the tree's productivity where the lowest prunes were left to support the fruit.

\section{Satellite remote sensing image}

The World View satellite with World View-3 sensor is currently available to use. The WV-3 sensor provides a high resolution and full-colour images to enhance spectral analysis, mapping and monitoring applications, land-use planning, disaster relief, exploration, defence and intelligence, and visualization and simulation environments (Satellite Imaging Corporation, 2017). Since the WV-3 images provided in .tiff format were already pre-processed by the supplier, the images were then immediately subjected to post processing in ArcGIS. As the images were not geographically correct, georeferencing was first performed using the Georeferencing tool in ArcGIS by comparing the images with google map. Three different images based on the study areas were studied and processed.

\section{Band combination for land feature discrimination}

WV-3 satellite comprises of eight multispectral bands ranging from $400 \mathrm{~nm}$ to $1040 \mathrm{~nm}$, with panchromatic spectral range of $450-800 \mathrm{~nm}$. WorldView-3 satellite bears a strong resemblance to WV-2 launched on October 8, 2009, in terms of its performance characteristics (DigitalGlobe, 2014). The WV-3 satellite sensor benefits from significant improvements including saving cost, risk reduction, and faster delivery for its customers.

The large number of bands offered by Worldview satellite generate a decent outcome for vegetation discrimination study. A study by Heenkenda et al. (2014) indeed discovered a large number of spectral bands with higher spatial resolution (pan-sharpened image) in WV2 more accurate than broad spectral bands within the blue, green, and red regions, when discriminating mangroves from other features in an image. For instance, recent study by Tian et al. (2017) has successfully employed the application of WV2 for mapping Leaf Area Index (LAI) for mangrove area in Guangxi province, China mangrove forests. This shows the capability of WV spectral bands for vegetation studies. In this study, multispectral bands were manipulated for the purpose of land cover classification with the inclusion of vegetation, land, water and building in the area based on a pre-visit to the study sites. The study site is located nearby the settlements area along with a small river in the area. The study of multispectral bands application was employed based on referenced application in geocarto apps which is available at http://www.geocarto.com.hk/edu/PJ-BCMBWV3G/main BCW3.html. The apps that generate multispectral bands combination eases larger satellite image number of bands.

WV began its success story for research in the beginning 2007 for mapping land resources by (Melesse et al., 2007), followed by many studies after that. Our study employed a combination of natural colour 5, 3, 2 (red, green, blue) for oil palm plantation to investigate 
Sheriza M.R ., Nurul Fatin M., Ainuddin, N.A : Application of remote sensing to assess the biophysical characteristics of palm oil trees for ecological study

the greenness of the canopy within the same age of the canopy. For false colour composite, we employed a combination of red colour 7, 5, 3 (Near-infrared1, red, green) combination with vegetation that would appeared as red colour because of the near-infrared wavelengths (NIR1). After that, we combined 8, 4, 1 (NIR2, Yellow and Coastal new bands in WV2 onwards) and 8, 7, 6 (NIR2, NIR1, Red edge).

\section{Biophysical characteristics of oil palm tree}

The biomass of oil palm was observed at the plantation of Felcra Mendom $1 \& 2$ in the districts. We have also reviewed other location, specifically on the north of the peninsular opposite to Raja Musa Forest Reserve. The management responded to our request timely; and since the location is located near our institution, we determined the location as appropriate to conduct our study. Accordingly, well grown trees at the site was specifically determined as the criteria for sampling selection. Approximately 120 trees were taken as samples from 24 plots, each consists of 10-12 trees. Dimension of all the plots were measured and GPS for the central points were recorded.

The bio-physical indicators of the samples include diameter at breast height (DBH), tree height $(\mathrm{H})$ and Leaf Area Index (LAI). Data for H was recorded by using Laser Ace1000 hypsometer that requires the user to stand approximately $10 \mathrm{~m}$ from the tree to enable the hypsometer provide the reading. LAI was recorded using indirect method of hemispherical images by estimating the age, LAI values were then derived from the ratio of canopy gaps to the sky (Chen et al. 1991). The hemispherical images were obtained using Nikon D5550 VBA 440AG set up with Sigma EX DG Fisheye $8 \mathrm{~mm}$ 1:3.5 lens and SLM type tripod. Image accuracy was enhanced by setting the hemispherical images at $0.8 \mathrm{~m}$ beneath the tree canopy. Images were taken under the diffuse skylight, normally after sunrise or immediately before sunset (Awal et al. 2010). After that, the hemispherical images were processed by using Gap Light Analyser (GLA) Version 2 software by converting the grey images into binary of 1-bit image according to user defined threshold and LAI calculation (Figure 3).

\section{Fig. 3: LAI measurement techniques}

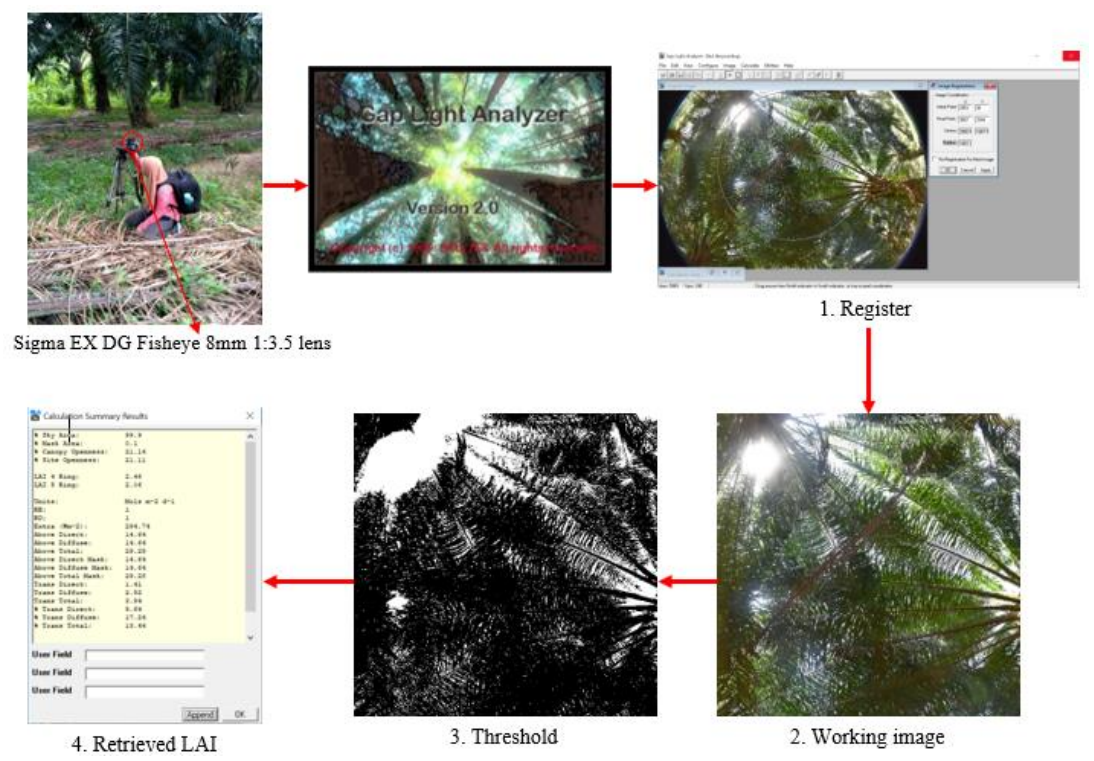


LAI was recorded to examine the relationships between the height and DBH of the oil palm trees. To further explore how height, DBH and LAI varied with elevation, interpolation of the elevation layer was performed based on kriging interpolation in Spatial Analyst tools.

\section{RESULTS}

\section{Land discrimination based on band combination}

The combined natural bands were visualized as a natural eye. This is because the ground features resulted from the combination of the visible bands appear similar to the human visual system (DigitalGlobe, 2014). Palm canopies appeared as green indicated a healthy vegetation, whereas shrubs surrounding the palms were indicated by lighter green. Heterogeneity of the trees in the peat swamp area differentiated the land from natural forest. Also, the palm expectedly appeared in green colour as large clumps due to the heterogeneity of the palm canopy, whereas the shrubs appeared similar to non-intact shapes of cauliflower. Both secondary roads and building appeared as grey colour. In this study, unhealthy palm trees appeared yellowish and brown colour. Interestingly, the false colour combination of NIR1, red and green bands shows that the canopy of healthy oil palm as dark red while open and the absence of vegetation appeared as turquoise colour. Shrubs appeared in light red to dark pinkly colour (Figure 4.).

Fig. 4: Natural colour map (L) and the combination colour of NIR1, red, green colour (R)
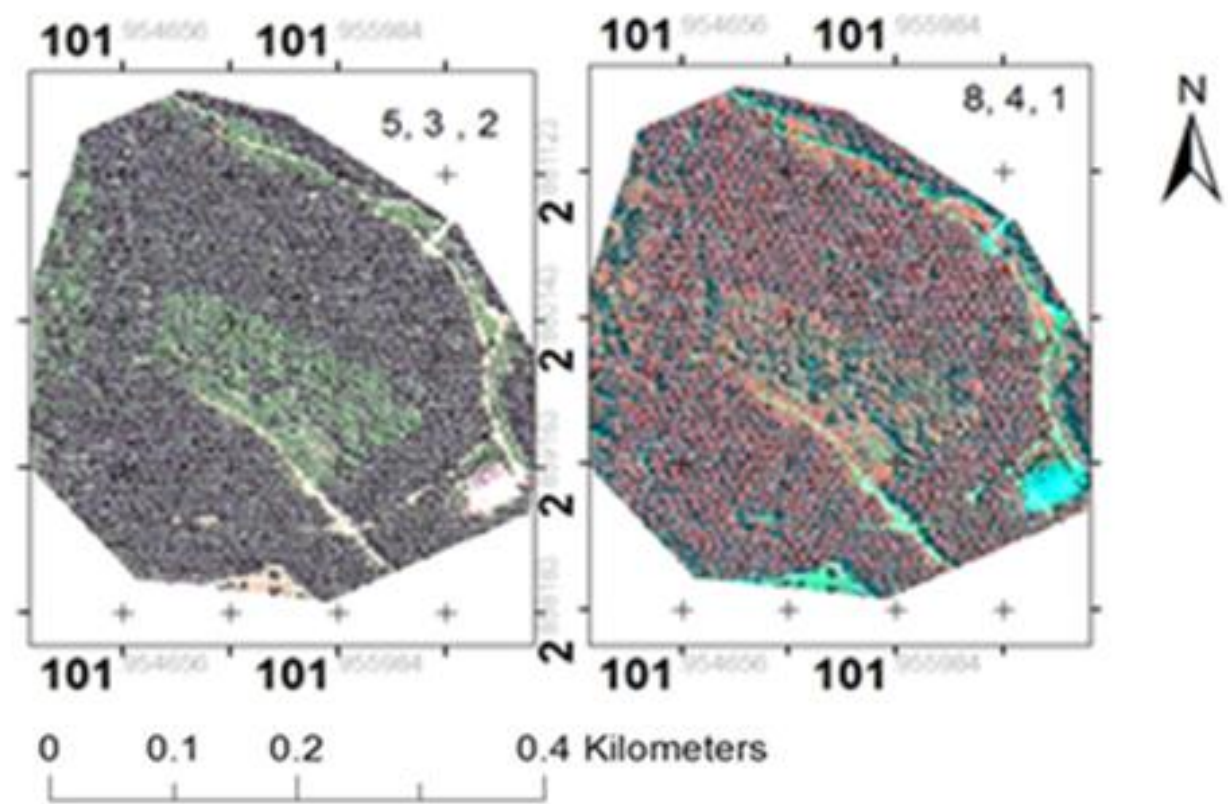
Sheriza M.R ., Nurul Fatin M., Ainuddin, N.A : Application of remote sensing to assess the biophysical characteristics of palm oil trees for ecological study

For NIR2, yellow, coastal combination of broad range of colours clearly distinguished different types of land cover. This characteristic is similar to the natural colour combination due to NIR band employed. Instantaneously, the combination easily recognised dissimilar characteristics on the patterns of vegetation on the land. The map showed vegetation in red, build up in blue. The NIR1, NIR2, and red-edge combination showed that NIR1 and NIR2 delineated oil palm canopy in yellowish green and other vegetation type in purple colour. This is attributed to the presence of red-edge spectrum bands in the combination (Figure 5).

Fig. 5: NIR2, yellow and coastal map (L) and the NIR1, NIR2, red-edge colour combination $(\mathbf{R})$
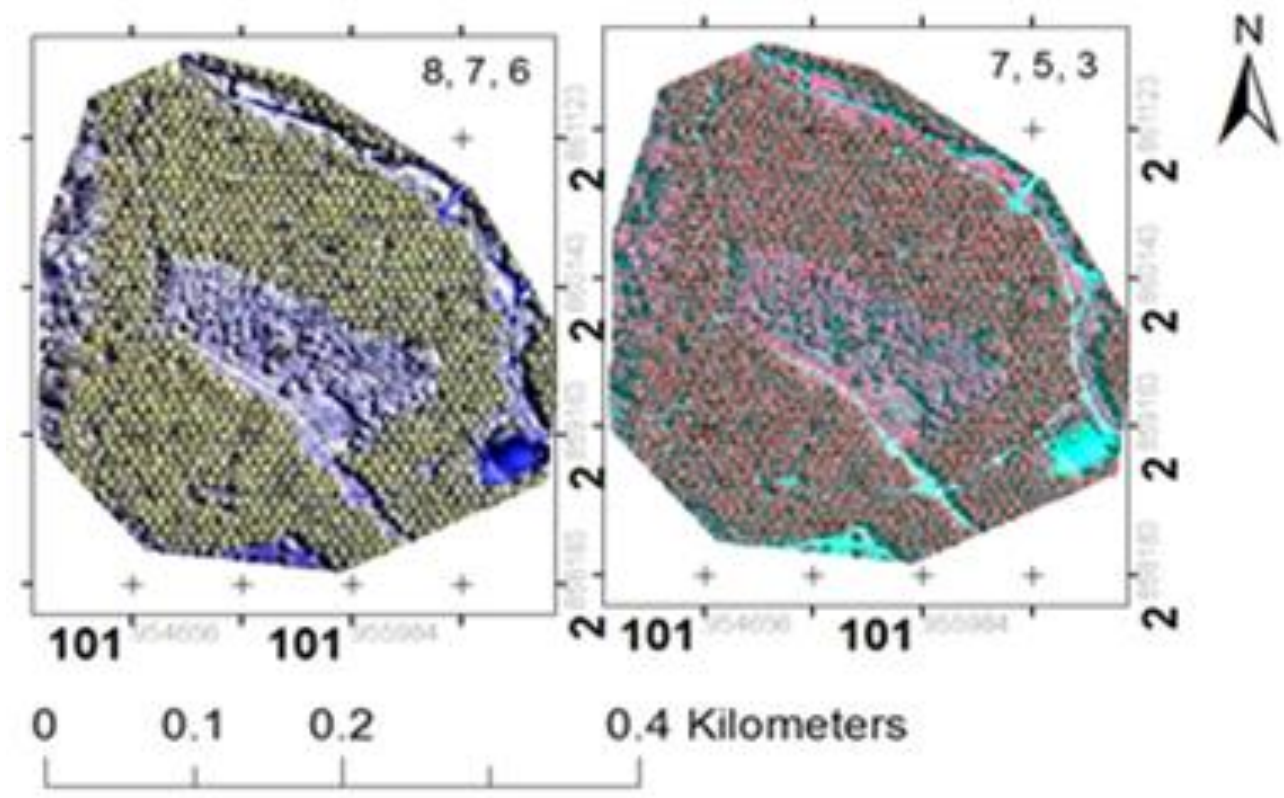

\section{Stands characteristics}

Collapsed trees on the ground as observed during the tree measurement may be attributed to non-productive trees or a consequence of infected stands. This is evidenced by the fact that they have survived for 16 years, which this is a further indication of the successful management of the plantation (Table 1). Most importantly, the plantation area adopts Good Agricultural Practice (GAP). 
Table 1: Height and dbh for the study site

\begin{tabular}{|c|c|c|}
\hline Plot No. & Mean height & Mean dbh \\
\hline 1 & 4.412727 & 0.71540 \\
\hline 2 & 5.878889 & 0.60746 \\
\hline 3 & 5.64 & 0.52728 \\
\hline 4 & 4.466667 & 0.62701 \\
\hline 5 & 4.212222 & 0.60155 \\
\hline 6 & 3.67375 & 0.59492 \\
\hline 7 & 4.194444 & 0.64054 \\
\hline 8 & 4.457778 & 0.60108 \\
\hline 9 & 4.805556 & 0.63848 \\
\hline 10 & 5.288889 & 0.60983 \\
\hline 11 & 4.37 & 0.65784 \\
\hline 12 & 4.084444 & 0.66368 \\
\hline 13 & 3.203 & 0.70108 \\
\hline 14 & 3.760833 & 0.84273 \\
\hline 15 & 3.414444 & 0.62495 \\
\hline 16 & 3.888889 & 0.63132 \\
\hline 17 & 4.376364 & 0.68357 \\
\hline 18 & 3.326667 & 0.58198 \\
\hline 19 & 4.073636 & 0.67004 \\
\hline 20 & 3.754444 & 0.59047 \\
\hline 21 & 3.846667 & 0.64007 \\
\hline 22 & 4.177778 & 0.58224 \\
\hline 23 & 3.572222 & 0.66182 \\
\hline 24 & 4.014444 & 0.65307 \\
\hline
\end{tabular}

The average mean height for the sample was 4.21 meter and dbh was 0.64 meters. The relationship between height and dbh in this study is depicted in Figure 6 . The study found that higher palm tree does not necessarily reflect the size of the palms. Variance for height was 0.450 and dbh was 0.004 . Nevertheless, the palms showed huge similarity in dbh size, which may be attributed to the equal treatment received by the plants, for example, the rate of fertilizer that accelerates higher photosynthesis productivity. Mean LAI for this study was 2.31, whereas the LAI variance was very low due to the narrow dispersion of the values, presumably because of the similar age of the trees. 
Sheriza M.R ., Nurul Fatin M., Ainuddin, N.A : Application of remote sensing to assess the biophysical characteristics of palm oil trees for ecological study

Fig. 6: Relationship between height and dbh

\section{Height vs dbh}

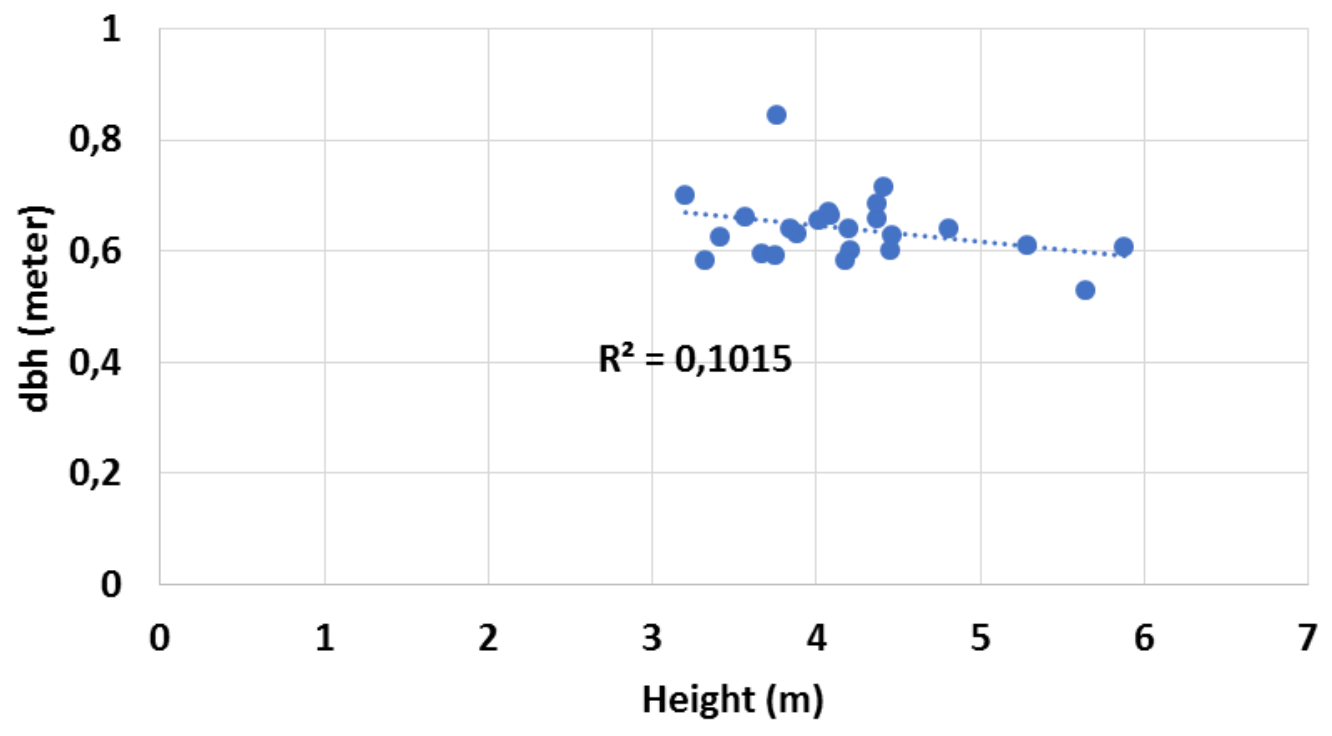

Table 2: t-Test for Paired Two-Sample means

\begin{tabular}{|l|l|r|r|r|}
\hline Parameters & & $\mathrm{H}(\mathrm{m})$ & $\mathrm{dbh}(\mathrm{m})$ & LAI \\
\hline & Mean & 4.21 & 0.64 & 2.31 \\
\hline & Variance & 0.450 & 0.004 & 0.176 \\
\hline & Observations & 24 & 24 & 24 \\
\hline
\end{tabular}

While the mean was 0.64 , the dbh clustered between 0.6 and 0.7 (Figure 7). Several points were dispersed at the upper part of the line that developed negative relationships, $\mathrm{R}^{2}=-0.0313$. Hence, we found that the study did not demonstrate an obvious relationship between LAI and dbh because of the number of samples obtained per plot for this study was insufficient. 
Fig. 7: Relationships between LAI and dbh

LAI vs dbh

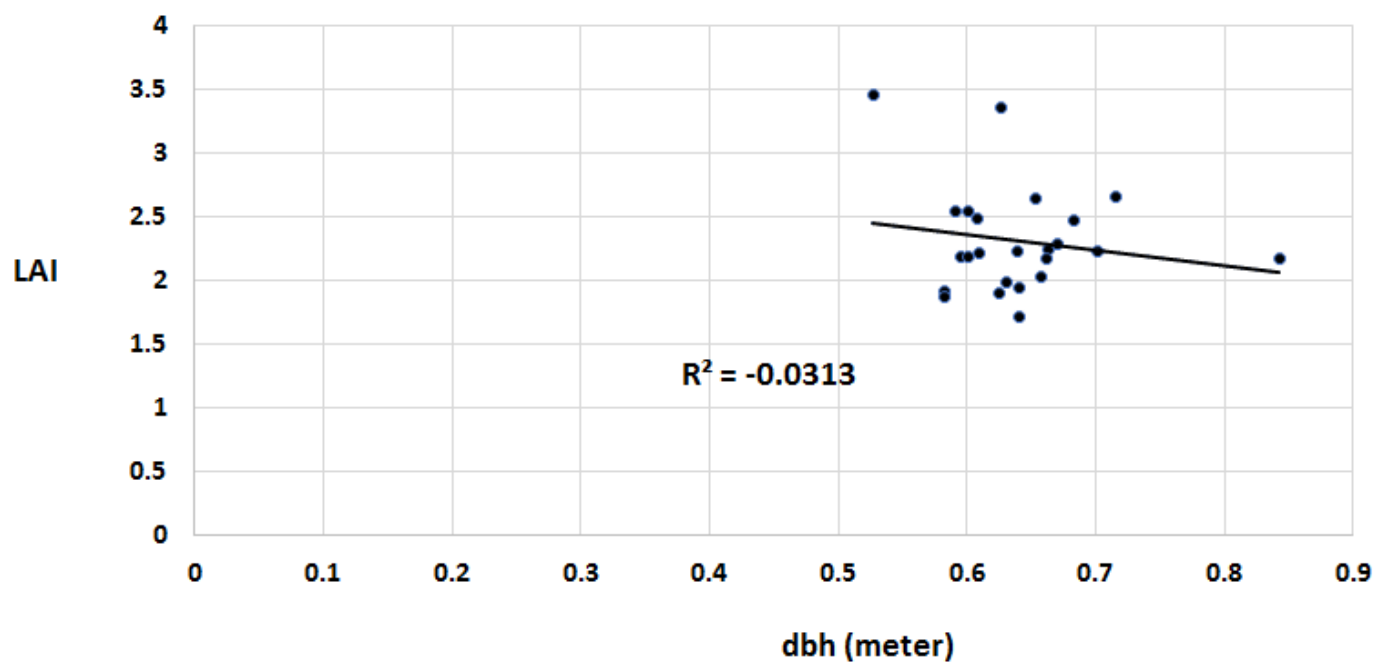

Height was positively associated with LAI (Figure 8), a bit a weaker relationship, $\mathrm{R}^{2}=0.2323$. Points plotted dispersed equally on the upper and lower part of the line, thereby illustrating better relationship than depicted in LAI and dbh.

\section{Fig. 8: Relationship between LAI and height}

\section{LAI vs height}

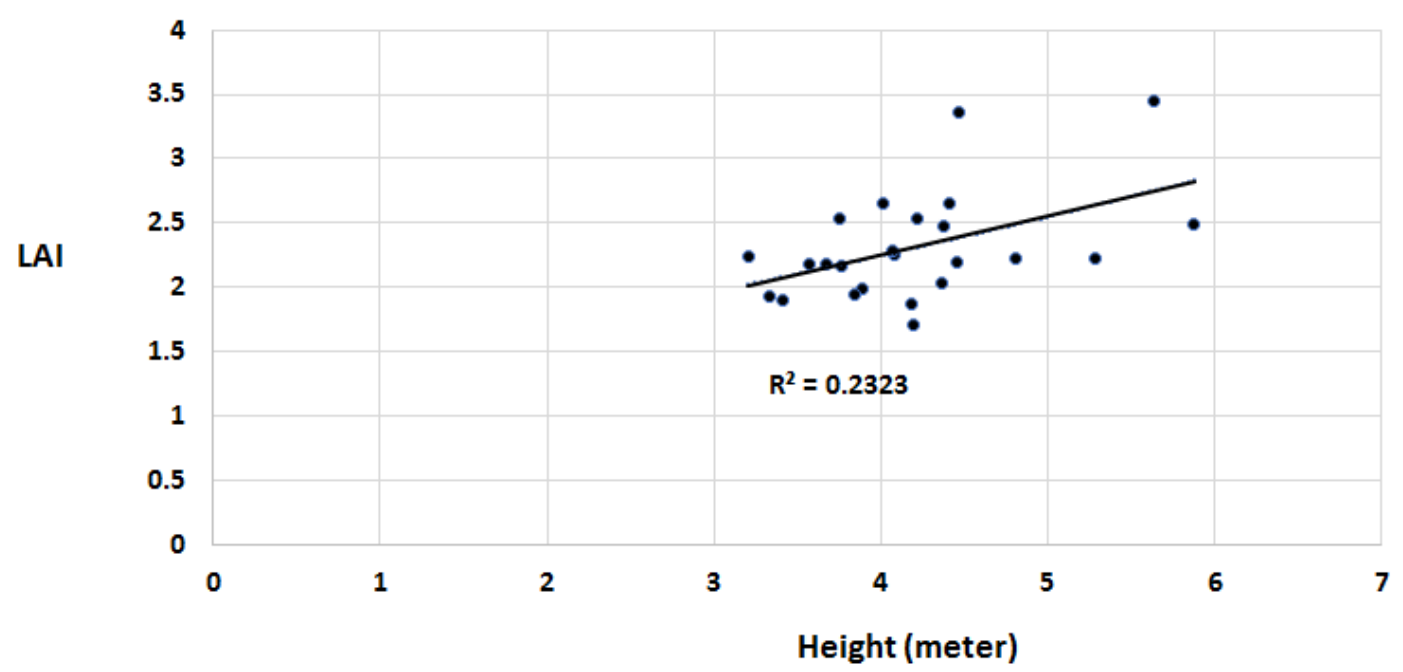

The elevation map showed ranges between 80.24 meter to 92.50 meter. A total number of 8 plots was developed at the highest elevation, namely plot no. 1 and 2, and 15-20. On the other 
Sheriza M.R ., Nurul Fatin M., Ainuddin, N.A : Application of remote sensing to assess the biophysical characteristics of palm oil trees for ecological study

hand, the lowest elevation comprised of 6 plots, namely plot no. 4 to 7 , and 13 and 14. The moderate elevation consisted of 6 plots, from plot no. 8 to 12. Figure 9 shows the elevation and plot arrangements of the study site.

Fig. 9: Elevation and bar chart of height, dbh and LAI for all the 24 plots overlaid on the satellite image



Based on our results, height is a physical parameter that can be a good indicator of LAI provided sufficient data collected for the study. The study site can be categorized as a fertile site capable of cultivating 148 trees per hectare, as found in the study by Conley \& Thinker (2008). 


\section{DISCUSSION}

The physical characteristics of the tree can be evaluated by analysing the dbh and the height of the oil palm in the plantation. As demonstrated in this study, larger number of samples may strengthen the relationships of the physical characteristics of the palm trees in the study. The study also showed that the height is a complete characteristic that can be used to determine tree growth and biomass. Height has also proven to be a potentially reliable indicator for the estimation of oil palm age (Chong et al., 2017). According to Sumida et al. (2013), both height and dbh are commonly used for tree growth measurement.

We also demonstrated that very low variance for dbh can be associated to the study performed by Chong et al. (2017). Based on the finding, the trunks of oil palms rarely thickened during the first two years, which explains the small differences in dbh found in the present study (Corley \& Tinker, 2008), except if the plants were treated by a different fertilizer. Therefore, we anticipated that low variance in palms may be attributed to the equal treatment received by the palms i. e. rate of fertilizer that produces uniform rate of photosynthesis activity, hence the palms achieved similar trunk size. Therefore, the best planting material combined with balance fertilization application as well as proper agronomic practices should be adopted by smallholder farmers (Barcelos et al., 2015).

Interestingly, a study by Roslan et al. (2004) found that LAI is influenced by the number of fronds and therefore, higher fronds should hold higher LAI value. Activities such as pruning and planting can also affect the maximum value of LAI, that is, reduced LAI. The LAI value reported in this study was consistent with other studies conducted in oil palm field plots in the Malay Peninsula (Awal et al., 2010). Presumably, this may be attributed to the similar age of the trees assessed in this study. Another study by Roslan et al. (2004) found lower mean LAI between 3.0 to 6.0. Meanwhile, LAI is heavily influenced by several environmental and management factors such as age, carbon balance, soil condition and fertilizer and weather (Roslan et al., 2004). LAI remains as a favourable parameter in determining palm tree age (Hardwick et al., 2015).

We found that the best band combination to highlight oil palm from other vegetation is by combining the band of $8,7,6$, which shows the oil palm crown at the highest contrast. Without further arguments, remote sensing enables the delineation of land cover, particularly highlighting oil palm by using certain bands available in satellite image.

There are several by-products from oil palm and these include oil palm trunk (OPT), oil palm fronds (OPF), empty fruit bunches (EFB), palm kernel cake (PKC), palm oil mill effluent (POME) and palm press fibre (PPF) (Zahari et al., n.d.). These are important for raw production or for products development. This study demonstrates its relevance, especially towards sustainable production and supply of oil palms for various product development. Environmental and disease that are capable of reducing the oil palm production can be benefitted from the continuous monitoring and thereby, enabling sustainability of palm production. As a matter of fact, despite being a highly significant crop in many countries, oil palm is prone to a rot disease caused by the fungus (Paterson, 2007). It is even reported that approximately $60 \%$ of plantations in Malaysia are infected by the disease (Barcelos et al., 2005). 
Sheriza M.R ., Nurul Fatin M., Ainuddin, N.A : Application of remote sensing to assess the biophysical characteristics of palm oil trees for ecological study

\section{CONCLUSION}

In conclusion, it is feasible to perform the study on height, dbh and LAI as a biophysical characteristic to oil palm as it is globally important. In this study, oil palm plantation was delineated, and other land cover was identified based on the satellite assessed. Plant characteristics remained as the potential indicator for tree growth for monitoring its productivity. As plant breeders, smallholders and large companies of oil palm plantation continue with their efforts to increase primary productivity, this type of study is, therefore, beneficial to global oil palm industry.

\section{ACKNOWLEDGEMENT}

This research was supported by Research University grant of University Putra Malaysia (Vote No. 9542100). We thank Prof. Ahmad Ainuddin Nuruddin for assisting us in developing sampling methodology and also be our research inspiration. We would also like to show our gratitude to Felcra Mendom manager for providing their time during the course of this project.

\section{REFERENCES}

Awal, M. A., Wan Ishak, W. I., \& Bockari-Gevao, S. M. (2010). Determination of leaf area index for oil palm plantation using hemispherical photography technique. Pertanika Journal of Science and Technology, 18(1), 23-32.

Barcelos, E., De Almeida Rios, S., Cunha, R. N. V., Lopes, R., Motoike, S. Y., Babiychuk, E., et al. (2015). Oil palm natural diversity and the potential for yield improvement. Frontiers in Plant Science, 6(MAR), 1-16. doi:10.3389/fpls.2015.00190

Bhuiyan, C., Singh, R. P., \& Kogan, F. N. (2006). Monitoring drought dynamics in the Aravalli region (India) using different indices based on ground and remote sensing data. International Journal of Applied Earth Observation and Geoinformation, 8(4), 289-302. doi:10.1016/j.jag.2006.03.002

Chen, J. M., Black, T. A., \& Adams, R. S. (1991). Evaluation of hemispherical photography for determining plant area index and geometry of a forest stand. Agricultural and Forest Meteorology, 56(1-2), 129-143. doi:10.1016/0168-1923(91)90108-3

Cheng, Y., Yu, L., Cracknell, A. P., \& Gong, P. (2016). Oil palm mapping using Landsat and PALSAR: a case study in Malaysia. International Journal of Remote Sensing, 37(22), 54315442. doi:10.1080/01431161.2016.1241448

Cheng, Y., Yu, L., Xu, Y., Lu, H., Cracknell, A. P., Kanniah, K., \& Gong, P. (2018). Mapping oil palm extent in Malaysia using ALOS-2 PALSAR-2 data. International Journal of Remote Sensing, 39(2), 432-452. doi:10.1080/01431161.2017.1387309

Chong, K. L., Kanniah, K. D., Pohl, C., \& Tan, K. P. (2017). A review of remote sensing applications for oil palm studies. Geo-spatial Information Science, 20(2), 184-200. doi:10.1080/10095020.2017.1337317

Corley, R. H. V., \& Tinker, P. B. (2003). The Palm Oil (4th ed.). Oxford: Blackwell Publishing.DigitalGlobe. (2014). World View- 3 Design and Specifications, 1-2.

Galvão, L. S., dos Santos, J. R., Roberts, D. A., Breunig, F. M., Toomey, M., \& de Moura, Y. 
M. (2011). On intra-annual EVI variability in the dry season of tropical forest: A case study with MODIS and hyperspectral data. Remote Sensing of Environment, 115(9), 2350-2359. doi:10.1016/j.rse.2011.04.035

Hardwick, S. R., Toumi, R., Pfeifer, M., Turner, E. C., Nilus, R., \& Ewers, R. M. (2015). The relationship between leaf area index and microclimate in tropical forest and oil palm plantation: Forest disturbance drives changes in microclimate. Agricultural and Forest Meteorology, 201, 187-195. doi:10.1016/j.agrformet.2014.11.010

Heenkenda, M. K., Joyce, K. E., Maier, S. W., \& Bartolo, R. (2014). Mangrove species identification: Comparing WorldView-2 with aerial photographs. Remote Sensing, 6(7), 6064-6088. doi:10.3390/rs6076064

Jamaludin Suhaila, Sayang Mohd Deni, Wan Zawiah Wan Zin, Jemain, A. A., Jamaludin, S., Mohd Deni, S., et al. (2010). Trends in Peninsular Malaysia Rainfall Data During the Southwest Monsoon and Northeast Monsoon Seasons : 1975 - 2004. Sains Malaysiana, 39(4), 533-542.

Longépé, N., Rakwatin, P., Isoguchi, O., Shimada, M., Uryu, Y., \& Yulianto, K. (2011). Assessment of ALOS PALSAR $50 \mathrm{~m}$ orthorectified FBD data for regional land cover classification by support vector machines. IEEE Transactions on Geoscience and Remote Sensing, 49(6 PART 1), 2135-2150. doi:10.1109/TGRS.2010.2102041

Melesse, A. M., Weng, Q., Thenkabail, P. S., \& Senay, G. B. (2007). Remote Sensing Sensors and Applications in Environmental Resources Mapping and Modelling. Sensors, 7(12), 3209-3241. doi:10.3390/s7123209

Mohd Razali, S., Marin Atucha, A. A., Nuruddin, A. A., Abdul Hamid, H., \& Mohd Shafri, H. Z. (2015). Monitoring vegetation drought using MODIS remote sensing indices for natural forest and plantation areas. Journal of Spatial Science, 1-16. doi:10.1080/14498596.2015.1084247

MPOB. (2020). Overview of the Malaysian Oil Palm Industry 2019. Malaysian Palm Oil Board, (January), 1-4. doi:10.1017/CBO9781107415324.004

Paterson, R. R. M. (2007). Ganoderma disease of oil palm-A white rot perspective necessary for integrated control, Crop Protection, Vol. 26, pp. 1367 - 1376.

Razali, S. M., Atucha, A. A. M., Nuruddin, A. A., Shafri, H. Z. M., \& Hamid, H. A. (2015). Mapping Human Impact on Net Primary Productivity Using MODIS Data for Better Policy Making. Applied Spatial Analysis and Policy. doi:10.1007/s12061-015-9156-0

Roslan, M., Noor, M., \& Harun, M. H. (2004). The Role of Leaf Area Index (LAI) in Oil Palm. Oil Palm Bulletin, 48(May), 11-16.

Ross, J. 1981, The radiation regime and architecture of plant stands, Springer Netherlands, Dr W. Junk Publishers, The Hague, XXVII, 391, DOI: 10.1007/978-94-009-8647-3.

Satellite Imaging Corporation. (2017). WorldView-2 Satellite Sensor. http://www.satimagingcorp.com/satellite-sensors/worldview-2/

Sheldon, S., Xiao, X., \& Biradar, C. (2012). Mapping evergreen forests in the Brazilian Amazon using MODIS and PALSAR 500-m mosaic imagery. ISPRS Journal of Photogrammetry and Remote Sensing, 74, 34-40. doi:10.1016/j.isprsjprs.2012.07.003

Sumida, A., Miyaura, T., \& Torii, H. (2013). Relationships of tree height and diameter at breast height revisited: Analyses of stem growth using 20-year data of an even-aged Chamaecyparis obtusa stand. Tree Physiology, 33(1), 106-118. doi:10.1093/treephys/tps127

Tan, K. P., Kanniah, K. D., \& Cracknell, A. P. (2014). International Journal of Remote On 
Sheriza M.R ., Nurul Fatin M., Ainuddin, N.A : Application of remote sensing to assess the biophysical characteristics of palm oil trees for ecological study

the upstream inputs into the MODIS primary productivity products using biometric data from oil palm plantations. International Journal of Remote Sensing, (October 2014), 37-41. doi:10.1080/01431161.2014.889865

Tian, J., Wang, L., Li, X., Gong, H., Shi, C., \& Zhong, R. (2017). Int J Appl Earth Obs Geoinformation Comparison of UAV and WorldView-2 imagery for mapping leaf area index of mangrove forest. Int J Appl Earth Obs Geoinformation, 61(October 2016), 22-31. doi:10.1016/j.jag.2017.05.002

Watson, D. J. (1947). Comparative Physiological Studies on the Growth of Field Crops: II. The Effect of Varying Nutrient Supply on Net Assimilation Rate and Leaf Area. Annals of Botani, New Series, Vol. 11, No. 44 (October, 1947), Oxford University Press., pp. 375-407 (33 pages).

Wan Zin, W. Z., Jemain, A. A., \& Ibrahim, K. (2013). Analysis of drought condition and risk in Peninsular Malaysia using Standardised Precipitation Index. Theoretical and Applied Climatology, 111(3-4), 559-568. doi:10.1007/s00704-012-0682-2

Zahari, M. W., Hassan, O. A., Wong, H. K., Liang, J. B., \& Livestock, S. (n.d.). Utilization of Oil Palm Frond - Based Diets for Beef and Dairy Production in.

Zheng, G., \& Moskal, L. M. (2009). Retrieving Leaf Area Index (LAI) Using Remote Sensing: Theories, Methods and Sensors. Sensors, 9(4), 2719-2745. doi:10.3390/s90402719 